\title{
Growth Spillover Effects and Regional Development Patterns: The Case of Chinese Provinces
}

\author{
Xubei Luo*
}

\begin{abstract}
:
This paper discusses regional development patterns in China, and examines effective ways of using development aid to attain regional balanced growth through optimizing growth spillover effects.

Based on provincial panel data from 1978 to 99, the paper constructs an indicator "neighbor performance" to measure the geographic spillover effects of aggregate growth from and to different provinces according to their relative richness and geographic position. Analysis of a Solow-type growth model suggests that positive spillover effects dominate negative shadow effects at the national level as well as the regional level; and some coastal provinces provide growth pull and growth push forces for their neighbors and serve as locomotives.

The results show that the rapid take-off of the coastal provinces has the largest spillover effects on the entire Chinese economy, but at the expense of a widening regional gap. A policy of encouraging the growth of the non-coastal regional hubs would have strong forward and backward linkages with the inland/western regions and thus reduce the regional development gap without sacrificing much aggregate growth. The paper offers support for the policy of developing inland hubs, and argues that directing development aid to Hubei and Sichuan would optimize the growth spillover impacts on inland regions.
\end{abstract}

JEL: O18, O47, R11

Key words: Spillover effects, Regional development pattern, Balanced growth, China

World Bank Policy Research Working Paper 3652, June 2005

The Policy Research Working Paper Series disseminates the findings of work in progress to encourage the exchange of ideas about development issues. An objective of the series is to get the findings out quickly, even if the presentations are less than fully polished. The papers carry the names of the authors and should be cited accordingly. The findings, interpretations, and conclusions expressed in this paper are entirely those of the authors. They do not necessarily represent the view of the World Bank, its Executive Directors, or the countries they represent. Policy Research Working Papers are available online at http://econ.worldbank.org.

\footnotetext{
*Email: xluo@worldbank.org; mailing address: World Bank, Office of Senior Vice President and Chief Economist, Development Economics, MSN MC4-404, 1818 H Street NW, Washington DC, 20433.
} 


\title{
Growth Spillover Effects and Regional Development Patterns: The Case of Chinese Provinces
}

\author{
Xubei Luo*
}

The Chinese economy has witnessed an unprecedented growth of more than $8 \%$ per annum since its reforms in 1978. However, the rapid take-off of the coastal provinces has widened the regional development gap. As shown in various studies, such as Naughton (1999) and Chen and Fleisher (1996), the dynamics of the coastal provinces and the relative stagnation of the inland provinces configure a center-periphery regional growth structure. Remoteness to the major economic centers limits the market accessibility of the inland (in particular, western) provinces, and impedes their growth performance (Luo, 2004). The growing disparity in income and standard of living may entail high social and economic cost and undermine long-term sustainability. Combining growth with a more balanced distribution of income has become one of the guiding tenets of the development plans of the Government of China. Since the late 1990s, encouraging the catching-up of the inland provinces - “develop the West (1999)”, “develop the NorthEast (2003)”, and “develop the Central (2005)” - has been a focus of regional development strategies of the Chinese government.

This paper studies the effectiveness of the regional growth pattern in China and examines ways to attain regional balanced growth without too much compromising this effectiveness through geographic spillover effects. It argues the importance of sequencing development aid to optimize growth spillover effects and prioritizing the development of some inland hubs in achieving the regional development goal.

By measuring the "neighbor performance" of each province and by simulating the aggregate growth spillover effects of each province on the entire country and on different

\footnotetext{
* The author is grateful to David Dollar, Shahrokh Fardoust, Alan Gelb, Henri-François Henner, Bert Hofman, Louis Kuijs, Russell Pittman, Mark Sundberg, and Nong Zhu, for fruitful discussions and pertinent comments. The views expressed are those of the author, who is responsible for all remaining errors.
} 
regions, this paper addresses the following questions: 1 . Does the rapid take-off of the coastal province greatly encourage the growth of the entire Chinese economy, and which provinces benefit most from the growth spillover effects of the coastal provinces? 2. If the objective is to achieve regional balanced growth, which provinces should be prioritized in spurring growth to maximize the spillover effects in favor of the inland/western provinces?

As argued in Courcie and Lafay (1972), demand from partner economies plays an important role in local development. The input-output linkages lead to non-negligible interregional spillover effects. Impacts of satisfactory performance of one province on the others could be positive or negative: on the one hand, it may enlarge the market and stimulate capital/knowledge transfer in favor of its neighbors (positive spillover effects); on the other hand, it may empty its surroundings of economic activities through its strengthened competitiveness in product and labor markets (negative shadow effects). ${ }^{1}$ The rapid growth of a rich province may pull its poor neighbors through the channels of capital and technology transfer; and the rapid growth of a poor province may push its rich neighbors through material supply.

Given that economic interdependence between two provinces weakens as geographic distance increases (Eaton and Tamura, 1994; Eaton and Kortum, 1994), and given the significant border effect (Amiti and Javorcik, 2004; McCallum, 1995; Poncet, 2002), other things equal, we focus on studying the spillover/shadow effects between neighbor provinces that share common borders. Many studies on spillover effects focus on foreign direct investments or some specific sectors ${ }^{2}$. We examine the general growth spillover effect by studying the effect of economic performance of neighbor provinces on local growth. ${ }^{3}$ To capture the impact of the economic performance of a province on the others, which depends on the economic size of the provinces in question and the

\footnotetext{
${ }^{1}$ See Krugman (1993a; 1993b) for more discussion.

${ }^{2}$ See, for example, Zhang and Felminghan (2002), Chuang and Hsu (2004), Berthelemy and Demurger (2000), and Yilmaz et al. (2002).

${ }^{3}$ See, for example, Moreno and Trehan (1997) and Easterly and Levine (1995). The former argue that an economy's growth rate is positively influenced by the growth rate of the economies nearby, after controlling a set of variables commonly used to predict growth rates. The latter confirm a large growth spillover effect in a study of the growth experience of Africa.
} 
economic interdependence between them, we construct a series of indicators to measure the economic environment that a province faces.

Using panel provincial data from 1978 to 1999, this paper studies the spillover effects in the case of China, and came out with three findings: (1) at national and regional levels, the rapid growth of a province encourages that of the neighbors - the regional development is in a virtuous circle; ${ }^{4}$ (2) spillover effects differ in size and in significance among different province groups - some coastal provinces serve as growth locomotives; and (3) the rapid take-off of some coastal provinces in the last two decades did maximize aggregate growth of the entire economy, while encouraging growth in the inland hubs that have strong forward/backward linkages with other provinces is the most effective way of reducing the regional development gap.

The paper is organized as follows: section 1 describes the growth trajectories and the center-peripheral regional growth pattern between coastal and inland provinces; section 2 focuses on the construction of a series of indicators of "neighbor performance"; section 3 examines the differentiated spillover effects on local growth issued from and received by different provinces; section 4 simulates the impact of a hypothetical performance enhancement of various provinces on regional growth, examines the effectiveness of the regional growth pattern, and identifies the target locations of development aid. Finally, the paper concludes.

\section{Section 1: Center-peripheral unbalanced regional growth pattern}

The success of the Chinese economic reforms, which were launched in the late 1970s, is well documented in the literature. ${ }^{5}$ Through incrementally reforming the centrally planned system to improve incentives and increase the scope of the market in resource allocation, and through building new institutions to support a market system before old institutions were destroyed, China's transition has achieved a remarkable success (Qian, 2000; 2003). The GDP per capita of the Chinese provinces increased more than 5 times in average from 1978 to 1999 (table 1).

\footnotetext{
${ }^{4}$ Baumont et al. (2001) give a thorough discussion on the spillover effects and shows the positive geographic spillover in a study of the European regions.

${ }^{5}$ See, for example, Naughton (1995) and Renard (2002).
} 
Table 1 - Development level and growth rate of Chinese provinces

\begin{tabular}{|c|c|c|c|c|c|c|}
\hline \multirow[b]{2}{*}{ code } & \multirow[b]{2}{*}{ province } & \multicolumn{4}{|c|}{ GDP per capita (yuan 1978) } & \multirow{2}{*}{$\begin{array}{c}\begin{array}{c}\text { Average annual growth } \\
\text { rate }\end{array} \\
79-99 \\
\end{array}$} \\
\hline & & 1978 & 1985 & 1992 & 1999 & \\
\hline \multicolumn{7}{|c|}{ Coastal region } \\
\hline 1 & Beijing & 1249 & 2109 & 3358 & 6222 & $7.65 \%$ \\
\hline 2 & Tianjin & 1141 & 1941 & 2714 & 5656 & $7.62 \%$ \\
\hline 3 & Hebei & 362 & 586 & 994 & 2239 & $8.68 \%$ \\
\hline 6 & Liaoning & 675 & 1107 & 1759 & 3164 & $7.35 \%$ \\
\hline 9 & Shanghai & 2484 & 4032 & 6161 & 14065 & $8.26 \%$ \\
\hline 10 & Jiangsu & 427 & 872 & 1722 & 4082 & $10.75 \%$ \\
\hline 11 & Zhejiang & 330 & 805 & 1529 & 3796 & $11.63 \%$ \\
\hline 13 & Fujian & 271 & 567 & 1102 & 2895 & $11.29 \%$ \\
\hline 15 & Shandong & 315 & 614 & 1099 & 2614 & $10.08 \%$ \\
\hline 19 & Guangdong & 365 & 725 & 1637 & 3600 & $10.90 \%$ \\
\hline \multicolumn{7}{|c|}{ Central region } \\
\hline 4 & Shanxi & 363 & 637 & 905 & 1611 & $7.10 \%$ \\
\hline 5 & Nei Mongol. & 318 & 630 & 964 & 1747 & $8.11 \%$ \\
\hline 7 & Jilin & 381 & 668 & 1099 & 2115 & $8.16 \%$ \\
\hline 8 & Heilongjiang & 558 & 835 & 1218 & 2102 & $6.31 \%$ \\
\hline 12 & Anhui & 242 & 483 & 657 & 1548 & $8.84 \%$ \\
\hline 14 & Jiangxi & 273 & 488 & 781 & 1623 & $8.48 \%$ \\
\hline 16 & Henan & 231 & 453 & 702 & 1480 & $8.85 \%$ \\
\hline 17 & Hubei & 330 & 662 & 973 & 2108 & $8.83 \%$ \\
\hline 18 & Hunan & 285 & 463 & 702 & 1363 & $7.46 \%$ \\
\hline \multicolumn{7}{|c|}{ Western region } \\
\hline 20 & Guangxi & 223 & 334 & 534 & 1062 & $7.44 \%$ \\
\hline 21 & Sichuan & 252 & 475 & 737 & 1361 & $8.03 \%$ \\
\hline 22 & Guizhou & 174 & 326 & 472 & 765 & $7.07 \%$ \\
\hline 23 & Yunnan & 223 & 395 & 650 & 1141 & $7.77 \%$ \\
\hline 24 & Shaanxi & 292 & 500 & 782 & 1415 & $7.52 \%$ \\
\hline 25 & Gansu & 346 & 515 & 844 & 1487 & $6.94 \%$ \\
\hline 26 & Qinghai & 426 & 627 & 805 & 1355 & $5.51 \%$ \\
\hline 27 & Ningxia & 366 & 618 & 885 & 1531 & $6.82 \%$ \\
\hline 28 & Xinjiang & 317 & 621 & 1098 & 1769 & $8.19 \%$ \\
\hline
\end{tabular}

Data source: China Statistical Yearbook (various editions) and author's calculation. The data of Chongqing, a municipality established in 1997, is included into its original province Sichuan; and Hainan (an island province separated as an special economic zone from Guangdong in 1988) and Xizang are excluded for their special characteristics.

However, in the last two decades, the growth rate of the coastal provinces has been much higher than that of the western provinces. For example, Guangdong, Shanxi and Ningxia shared the similar development level in 1978, while thanks to the doubledigit average annual growth in more than 20 years, the GDP per capita of Guangdong was more than twice of its two inland partners in $1999 .{ }^{6}$ The coastal region became far

\footnotetext{
${ }^{6}$ According to the regional classification of the "Statistics of China's Fixed Assets and Investment 19501985," the Chinese provinces are classified into three categories: coastal, central, and west. The coastal region includes Liaoning, Hebei, Beijing, Tianjin, Shandong, Jiangsu, Shanghai, Zhejiang, Fujian,
} 
more developed than the inland region; among the inland provinces, the remote western provinces lagged further behind. ${ }^{7}$

The difference in annual growth results in the modification of the relative ranking of provincial development level. Here, we define the relative real GDP per capita $y r_{i, t}$ as:

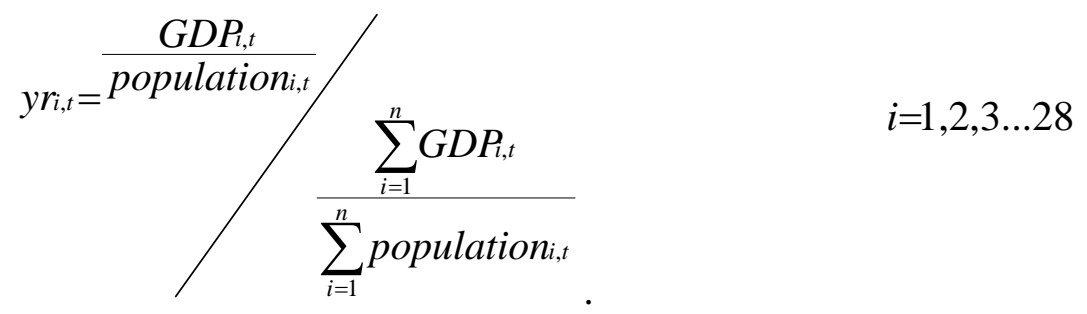

If $y r_{i, t}$ is superior to 1 , the development level of province $i$ is higher than the national average in year $t$; if $y r_{i, t}$ is inferior to 1 , the development level of province $i$ is lower than the national average in year $t$. Normalizing the GDP per capita of province $i$ by the average national GDP per capita, we find that the three municipalities always have a much higher relative development level than the other provinces - Tianjin's development level is at least 2.5 times the national average, Beijing around 3 times, and Shanghai around 6 times. Given their special characteristics (such as high urbanization rates, special economic policies, etc.), we separate these provinces from the other provinces as they are considered the richest group.

Using Epanechnikov Kernel density ${ }^{8}$, graph 1 describes the growth trajectories of the Chinese provinces, where the width of the arrows in the graph is proportional to the number of the provinces that follow the particular development trajectory (the change in

Guangdong, Hainan; the central region includes Heilongjiang, Jilin, Nei Mongol, Shanxi, Henan, Anhui, Hubei, Hunan, Jiangxi; the western region includes Guangxi, Shaanxi, Gansu, Ningxia, Qinghai, Xinjiang, Chongqing, Sichuan, Yunnan, Guizhou, Xizang. The central region and the western region are considered as the inland regions. See annex 1 for more details.

${ }^{7}$ Despite the rapid absolute growth compared with most economies worldwide, the inland provinces suffered a relative decline in the Chinese economy.

${ }^{8}$ The estimation of Kernel density of a series $\mathrm{X}$ in point $\mathrm{x}$ is defined as $f(x)=\frac{1}{N h} \sum_{i=1}^{N} K\left(\frac{x-X_{i}}{h}\right)$, where $N$ stands for the number of observations, $h$ the parameter of smoothness, and $K(\bullet)$ the function of Kernel where the integral is equal to unity 
group ranking). ${ }^{9}$ If the relative development level of many provinces is around 1 , that is to say, near the national average level, the distribution is egalitarian; if the relative development level of a large number of provinces concentrates in one extreme and that of the others concentrate in the other extreme, the regional development is unequal. ${ }^{10}$ Our results show that, apart from the three municipalities, in early 1980s, the relative development levels of the provinces tended to cluster around the national average, few provinces were much poorer or richer than the others - apart from the three provinces (Liaoning, Jiangsu, and Heilongjiang) that had a relative GDP per capital ratio higher than 1.3, all the other 22 provinces clustered together with the peak value around 1 (ie. around the national average level); however, in the late 1990s, the number of provinces whose development level is around the national average shrank to 7, the poor group emerged - 14 provinces clustered together with a peak value of 0.65 , and the number of the provinces belonging to the rich group slightly increased to $4 .{ }^{11}$

The graph 1 shows that (i) at the end of our period of study, all provinces belonging to the poor group were inland provinces (predominantly western provinces); and all provinces belonging to the rich group were costal provinces ${ }^{12}$; and (ii) during this period, all provinces that suffered a relative decline in ranking were inland provinces (predominantly western provinces), and all the provinces that caught up were coastal provinces. The Chinese provinces converged to different clubs - the coastal provinces clustered together to form the rich club, while the inland provinces declined to the level of periphery. The emergence of the two peaks, rich and poor (consisting of the coastal provinces and the remote inland provinces, respectively), vividly demonstrates the centerperipheral development pattern in China. ${ }^{13}$

\footnotetext{
${ }^{9}$ For the sake of simplicity and to smooth out the impact of short-term shocks, we examine the distribution of the provincial average relative GDP per capita of the first and the last seven years of our period of study (1978-1984 and 1992-1999). The evolution of annual relative provincial GDP per capita, 1978-1999, is available from the author upon request.

${ }^{10}$ See Ben-David (1994; 1997), Quah (1996; 1997), Cozzi (1997).

${ }^{11}$ Here, the groups (rich, intermediate, and poor) are classified in order to maximize the homogeneity of the relative GDP per capita level among the members in the same group, and the heterogeneity among members in different groups.

${ }^{12}$ The three municipalities are already separated as the richest group from the other provinces. For the reasons of readability, we do not illustrate these three provinces in graph 1.

${ }^{13}$ See Quah (1997; 1999), Desdoigts (1999).
} 
Graph 1 - Growth trajectories of Chinese provinces (1978-1999)

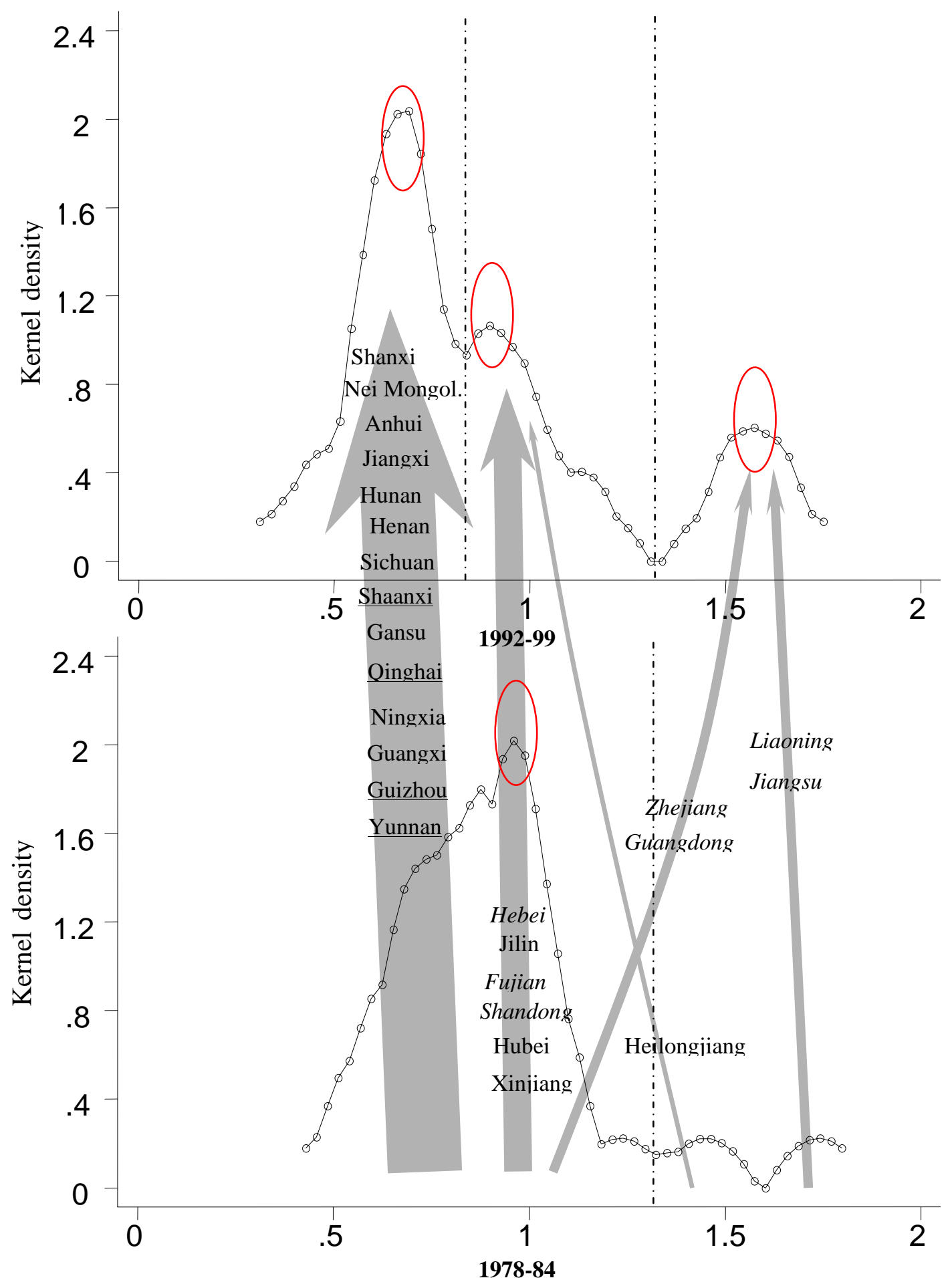

Relative GDP per capita

Note: Coastal provinces are marked in italic; western provinces are underlined. 
The following two questions are worth considering: (i) will the rapid development of the coastal provinces offer "growth pull" to the performance of the inland provinces, and the catching-up of the inland provinces offer "growth push" to the further development of the coastal provinces, or would they impede each other? (ii) which provinces generate the most favorable spillover effects on the entire Chinese economy, and on different regions? The sign and size of spillover effects are reviewed in the next sections.

\section{Section 2: Construction of the indicator "neighbor performance"}

To measure the influence that one province may receive from its partners, in other words, the general growth spillover/shadow effects that the immediate neighbor have on the performance of the province in question, we construct our indicator "neighbor performance", noted $G A W_{i, t}$, which is the weighted average of the growth rate of the neighbor provinces. The gravity model suggests that the farther away two economies are, the weaker their relationship is, others characteristics being equal. ${ }^{14}$ In this analysis, the neighbor provinces are limited to the ones that share common borders with the province in question. ${ }^{15}$

$$
G A W_{i, t}=\sum_{q=1}^{m_{i}}\left(g a_{q, t} \times \text { impor } \tan c e_{i, q, t}\right)
$$

where impor $\tan c e_{i, q, t}=\frac{G D P_{q, t}}{\sum_{q=1}^{m_{i}} G D P_{q, t}}, g a_{q, t}=\ln \left(y_{q, t}\right)-\ln \left(y_{q, t-1}\right), y_{q, t}$ stands for the real GDP per capita of the neighbor province $q$ in time $t$, and $m_{i}$ the number of the neighbor province of $i$. In our case, $m_{i}$ is an integer between 2 and $8 .{ }^{16}$ Here, the value of $G A W_{i, t}$ is conditioned on the growth rate of the neighbor provinces $q, g a_{q, t}$. The influence of the

\footnotetext{
${ }^{14}$ See, for example, Evenett and Keller (1998), Bergstrand (1985), and Deardorff (1995).

${ }^{15}$ For the sake of simplicity, we limit the "neighbors" as the provinces that share common borders, and do not take into account the linkages through inland waterway. Addressing the second round spillover effects and examining the impacts of inter-provincial migration structure on regional growth will be an interesting topic for further research.

${ }^{16}$ For example, Shanghai has only 2 neighbors (Zhejiang and Jiangsu); while, Sichuan has 8 neighbors (Gansu, Qinghai, Xizang, Yunnan, Guizhou, Hunan, Hubei, and Shaanxi).
} 
growth rate of each neighbor province $q$ is conditioned on its economic size of relative to all the $m_{i}$ provinces surrounding province $i$.

Spillover effects may vary in direction (positive/negative) and in size across different types of provinces, for example, it is probable that spillover effects from a poor inland neighbor and those from a rich coastal neighbor differ. In order to relax the hypothesis of the homogeneity of the spillover effects issued from (and received by) different provinces ${ }^{17}$, we classify neighbor provinces into different sub-groups according to two criteria: “criterion of richness" (whether a neighbor province is richer or poorer than the province in question) ${ }^{18}$; and “criterion of geographic region” (whether a neighbor province locates in the same geographic region of the province in question coastal/inland, or coastal/central/western).

According to the first criterion, we have two sub-categories of GAW indicators for a province $i: G A W R_{i, t}=\sum_{u=1}^{m R_{i, t}}\left(g a_{u, t} \times\right.$ impor tan $\left.c e R_{i, u, t}\right)$, for neighbor provinces richer than the province $i$; and $G A W P_{i, t}=\sum_{v=1}^{m P_{i, t}}\left(g a_{v, t} \times\right.$ impor tan $\left.c e P_{i, v, t}\right)$, for neighbor provinces poorer than the province $i{ }^{19}$ Similarly, according to the second criterion, we have another two sub-categories of $G A W$ indicators: $G A W M_{i, t}$ for neighbor provinces that

\footnotetext{
${ }^{17}$ Also, it increases the homogeneity of the neighbor provinces $q$ inside the subgroup, and better allows for the across-subgroup heterogeneity.

${ }^{18}$ If the GDP per capita of a neighbor province $q$ in year $t-1$ is higher than that of the province $i$, we consider province $q$ as a neighbor province that is richer than province $i$ when we construct the indicator $G A W_{i}$ at time $t$. Note that a neighbor province $q$ could be richer than province $i$ at time $t$, but poorer than province $i$ at time $t+s$, where $s \neq 0$, due to the change of the relative rankings of different provinces.

${ }^{19}$ Here, impor tance $R_{i, u, t}=\frac{G D P_{u, t}}{m R_{i t}}$ and impor tanceP $P_{i, v, t}=\frac{G D P_{v, t}}{m P_{i t}} \cdot m R_{i, t}$ stands for the

$$
\sum_{u=1}^{m R_{i, t}} G D P_{u, t} \quad \sum_{v=1}^{m P_{i, t}} G D P_{v, t}
$$
}

number of neighbor provinces of province $i$ that have a higher GDP per capita than province $i$ at time $t-1$, and $m P_{i, t}$ stands for the number of neighbor provinces that have a lower GDP per capita. 
are members of the same geographic region as the province $i$, and $G A W F_{i, t}$ for neighbor provinces that belong to a different geographic region. ${ }^{20}$

Therefore, one province $i$ may have up to four different types of neighbor provinces according to the two criteria. ${ }^{21}$ By construction, the weight of the growth rate of one neighbor province $q$ (impor $\tan c e_{i, q, t}$ ) is equal to the ratio of its economic size to the total economic size of the group of the neighbor provinces, noted that the sum of such weights are always equal to $1\left(\sum_{q=1}^{m_{i, t}}\right.$ impor $\left.\tan c e_{i, q, t}=1\right)$.

\section{Section 3: Spillover effects and regional growth}

In this section, we examine the spillover effects on regional growth by integrating the "neighbor performance" into the Solow-type growth model ${ }^{22}$ using the panel data at provincial level of the period of 1978-1999 from the China Statistical Yearbooks. In order to examine the net effects of economic performance of the neighbors, we control the traditional growth determinants - the initial development level $\left(y_{i, t-1}\right)$, investment rate $\left(s_{i, t}\right)$, demographic growth rate $\left(n_{i, t}\right)$. In order to capture the role of geo-economic position on regional growth, we introduce an indicator "peripheral degree", noted as $D P_{i, t}$, which equals to weighted average distance of one province to the domestic economic center adjusted by the development level of the infrastructure ${ }^{23}$. The results are

\footnotetext{
${ }^{20}$ Here, $M$ stands for the neighbor provinces that are members of the same geographic region of the province $i$ in question; while $F$ for the neighbor provinces that are members of a different geographic region.

${ }^{21}$ In fact, not each province has all the four different types of neighbor provinces. For example, Shanghai, the richest coastal province, which is surrounding by coastal provinces Jiangsu and Zhejiang, has only one type of neighbor provinces - the coastal neighbors that are poorer than itself ( $G A W C O M P_{i, t}$ ). In other words, in the case of Shanghai, the other three indicators $G A W C O M R_{i, t}, G A W C O F R_{i, t}$ and
} $G A W C O F P_{i, t}$ have no value. Therefore, the number of different types of neighbor province varies between 1 and 4 .

${ }^{22}$ See, for example, Barro (1991), Barro and Sala-i-Martin (1995).

${ }^{23}$ See Annex 2 for the construction of the indicator "peripheral degree", and see Luo $(2001 ; 2004)$ for further discussions. This indicator measures the market accessibility of the province in question. 
based on fixed-effects estimations. ${ }^{24}$ Equation 1 of table $2^{25}$ shows that higher initial development level implies a lower growth rate, while demographic growth tends to reduce growth. ${ }^{26}$ The farther away one province is from economic centres, the lower its growth rate is.

$$
\begin{aligned}
\ln \left(y_{i, t}\right)-\ln \left(y_{i, t-1}\right)=\quad & \alpha+\rho \ln \left(y_{i, t-1}\right)+\theta \ln \left(D P_{i, t}\right)+\gamma \ln \left(s_{i, t}\right)+\zeta \ln \left(n_{i, t}\right) \\
& +\sum_{t=1979}^{1998} \chi_{t} \text { dummy }_{t}+\varepsilon_{i, t}
\end{aligned}
$$

\begin{tabular}{|c|c|c|c|c|c|c|}
\hline \multicolumn{7}{|c|}{ Dependent variable : $\ln \left(y_{i, t}\right)-\ln \left(y_{i, t-1}\right)$} \\
\hline & (1) & (2) & (3) & $\left(3^{\prime}\right)$ & (4) & $\left(4^{\prime}\right)$ \\
\hline \multirow{2}{*}{$\ln \left(y_{i, t-1}\right)$} & $-0.070 * * *$ & $-0.074 * * *$ & $-0.077 * * *$ & $-0.075 * * *$ & $-0.066 * * *$ & $-0.063 * * *$ \\
\hline & $(-4.62)$ & $(-4.98)$ & $(-4.01)$ & $(-3.91)$ & $(-4.21)$ & $(-3.98)$ \\
\hline \multirow[t]{2}{*}{$\ln \left(D P_{1, t}\right)$} & $-0.169 * * *$ & $-0.157 * * *$ & $-0.150 * * *$ & $-0.161^{* *}$ & $-0.181^{* * *}$ & $-0.185^{* * *}$ \\
\hline & $(-3.44)$ & $(-3.25)$ & $(-2.27)$ & $(-2.45)$ & $(-3.69)$ & $(-3.75)$ \\
\hline \multirow[t]{2}{*}{$\ln \left(S_{i, t}\right)$} & 0.001 & 0.000 & -0.005 & -0.004 & -0.004 & -0.004 \\
\hline & $(0.11)$ & $(0.04)$ & $(-0.35)$ & $(-0.30)$ & $(-0.35)$ & $(-0.41)$ \\
\hline \multirow[t]{2}{*}{$\ln \left(n_{i, t}\right)$} & $-1.111^{* *}$ & $-1.048 * * *$ & $-1.462 * * *$ & $-1.522 * * *$ & $-1.011 * * *$ & $-1.047 * * *$ \\
\hline & $(-4.48)$ & $(-4.31)$ & $(-4.23)$ & $(-4.41)$ & $(-4.06)$ & $(-4.18)$ \\
\hline$G A W L_{i, t}$ & & $\begin{array}{c}0.330 * * * \\
(4.64)\end{array}$ & & & & \\
\hline$G A W R L i, t$ & & & $\begin{array}{l}0.138 * \\
(1.68)\end{array}$ & & & \\
\hline$G A W P L_{i, t}$ & & & & & $\begin{array}{c}0.152 * * * \\
(2.78)\end{array}$ & \\
\hline Constant & $\begin{array}{c}1.760 * * * \\
(3.91)\end{array}$ & $\begin{array}{c}1.637 * * * \\
(3.71)\end{array}$ & $\begin{array}{c}1.582 * * * \\
(2.63)\end{array}$ & $\begin{array}{c}1.692 * * * \\
(2.82)\end{array}$ & $\begin{array}{c}1.829 * * * \\
(4.09)\end{array}$ & $\begin{array}{c}1.867 * * * \\
(4.14)\end{array}$ \\
\hline $\begin{array}{l}\text { Observation } \\
\text { number }\end{array}$ & 547 & 547 & 395 & 395 & 507 & 507 \\
\hline $\begin{array}{l}\text { Adjusted R } \\
\text { square }\end{array}$ & 0.5707 & 0.5886 & 0.5780 & 0.5739 & 0.5897 & 0.5828 \\
\hline
\end{tabular}

Table 2 - Growth spillover effects of all Chinese provinces (1979-99)

Note: $t$-students are in parentheses. ${ }^{*}$ significant at 10 percent ; ${ }^{* *}$ significant at 5 percent ; ${ }^{* * *}$ significant at 1 percent.

\footnotetext{
${ }^{24}$ The limited number of observations does not allow carrying out the SURE estimations. The results of the two-step GMM estimations with two year-lagged dependent variables as IV matrix do not suggest the superiority of the GMM estimations over the fixed-effects estimations.

${ }^{25}$ We have also introduced year dummies to capture the effects of the common shocks that affect the growth performance of all provinces. For the sake of simplicity, the estimations of the dummies are not shown in the tables.

${ }^{26}$ Here, the role of investment on regional growth is not significant. Following the Solow growth theory, we do not drop this variable from the estimations.
} 
To capture the role that "economic environment" plays on growth, we introduce the indicator "neighbor performance" to equation 2. In order to minimize the problem of endogeneity and to take into account the delay of the effect of an increase in demand on growth, we use the lagged value of $G A W$, noted $G A W L$, where $G A W L_{i, t}=G A W_{i, t-1}$.

$$
\begin{aligned}
\ln \left(y_{i, t}\right)-\ln \left(y_{i, t-1}\right)= & \alpha+\rho \ln \left(y_{i, t-1}\right)+\theta \ln \left(D P_{i, t}\right)+\gamma \ln \left(s_{i, t}\right)+\zeta \ln \left(n_{i, t}\right) \\
& +\vartheta G A W L_{i, t}+\sum_{t=1979}^{1998} \chi_{t} \text { dummy }_{t}+\varepsilon_{i, t}
\end{aligned}
$$

The significant positive role of GAWL shows that, after controlling for the impacts of the other determinants of regional growth, the better the performance of the neighbour provinces, the higher the local growth rate. ${ }^{27}$

However, the similarity of spillover effects from and to different provinces seems to be a discussable hypothesis - for example, the spillover effects generated by a rich province on a poor neighbour may be different from those generated by a poor province on a rich neighbour. We examine the spillover effects from neighbour provinces richer than the province in question and those from neighbour provinces poorer than the province in question separately by introducing $G A W R L_{i, t}$ and $G A W P L_{i, t}$ into our model to replace $G A W L_{i, t}$.

$$
\begin{aligned}
\ln \left(y_{i, t}\right)-\ln \left(y_{i, t-1}\right)= & \alpha+\rho \ln \left(y_{i, t-1}\right)+\theta \ln \left(D P_{i, t}\right)+\gamma \ln \left(s_{i, t}\right)+\zeta \ln \left(n_{i, t}\right) \\
& +\vartheta G A W R L_{i, t}+\sum_{t=1979}^{1998} \chi_{t} d u m m y_{t}+\varepsilon_{i, t} \\
\ln \left(y_{i, t}\right)-\ln \left(y_{i, t-1}\right)= & \alpha+\rho \ln \left(y_{i, t-1}\right)+\theta \ln \left(D P_{i, t}\right)+\gamma \ln \left(s_{i, t}\right)+\zeta \ln \left(n_{i, t}\right) \\
& +\vartheta G A W P L_{i, t}+\sum_{t=1979}^{1998} \chi_{t} d_{u m m y_{t}}+\varepsilon_{i, t}
\end{aligned}
$$

The results of equations 3 and 4 suggest that the growth of the poorer provinces offers "push forces" to the neighbor provinces that are relatively richer, and the growth of the richer provinces offers "pull forces" to the neighbor provinces that are relatively

\footnotetext{
${ }^{27}$ We have estimated the spillover effects of the series of the indicators "neighbor performance" using the growth model without controlling the four growth determinants. The significance and the value of the coefficients of the indicators, so-called "gross spillover effects", are highly consistent with the ones estimated after controlling the growth determinants, the "net spillover effects". It suggests that our results are not sensitive to the inclusion of the other growth determinants. The results are available upon request.
} 
poorer. It corroborates the results in equation 2 and confirms the positive spillover effects among the Chinese provinces of different types.

However, the refining of the classification of neighbor provinces into homogenous sub-groups leads to the shrinkage of the sample size - some provinces are eliminated from particular subgroups because of their specific characteristics regarding the classification criteria. ${ }^{28}$ Equation 3' (4') confirms that regarding the role of the independent variables, the sub-samples are not significantly different from the wholesample, and the sub-samples are not significantly different between themselves. ${ }^{29}$ In other words, the spillover effects that our indicator "neighbor performance" captures are not sensitive to the sample modifications.

Given the significant role that geographic position plays on regional growth (Krugman 1991; 1998; Fujita et al. 1999; Reddings and Venables, 2000; Limao and Venables, 2001; Demurger et al., 2002, Bao et al.; 2003; Luo, 2004) and the large regional development gap in China, we further relax the hypothesis of the homogeneity of the spillover effects from and on provinces of different geographic regions - coastal versus inland (and central versus western) - and estimate the spillover effects in different regions separately.

Table 3 presents the result of spillover effects on the coastal provinces ${ }^{30}$. Equation 2 shows that, the growth of the neighbor coastal provinces encourages that of the coastal provinces in question ${ }^{31}$. However, the spillover effects are mainly the "pushing effects" from the neighbor provinces that are poorer than the province in question (equation 4$)^{32}$,

\footnotetext{
${ }^{28}$ For example, the richest provinces do not have neighbor provinces that are richer than themselves, and the poorest provinces do not have neighbor provinces which are poorer than themselves.

${ }^{29}$ The results of t-test suggest that the coefficients of the four growth determinants in equation 3' (4') are not significantly different from those in equation 3 (4).

${ }^{30}$ Equation 1 serves as the baseline comparison.

${ }^{31}$ Here, the effects of peripheral degree on growth are convex, as suggested in Luo (2004). In other words, the remoteness to economic centers plays a negative role on regional growth, while such negative effects decrease as peripheral degree increases. We keep the quadratic term $\left[\ln \left(D P_{, t}\right)\right] \times\left[\ln \left(D P_{t, t}\right)\right]$ and interactive term $[\ln (D P, t)] \times\left[\ln \left(y_{i, t-1}\right)\right]$ in our estimation for coastal provinces. Conclusion does not change much if we drop these two terms and use the equation for the whole nation to estimate the case of coastal region.

${ }^{32}$ The similarity of the size and sign of the coefficients of the controlling variables in our equations of interest (equations 2, 3, 4 and 5) and in the baseline equations (equations 2', 3', 4' and 5') supports the robustness of our results.
} 
while the development of the rich coastal provinces does not have significant "pulling effect". The existence of the "pushing effect" and the absence of the "pulling effect" suggest that the most advanced coastal centers tend to polarize. Equation 5 shows that the growth of the neighbor inland provinces does not significantly push the further development of the coastal neighbors.

Table 4 shows that the development of the inland neighbors and coastal neighbors both significantly encourages the development of the inland provinces. Given that the central provinces are richer than the western provinces as a whole, we classify the subgroup of inland provinces according to geographic position (central/western). Table 5 shows that among the central provinces, the development of one province encourages that of the others. In particular, the "pushing effects" of the central provinces that are relatively less advanced on the ones that are more advanced are more significant than "pulling effect" from the reversed direction. Many of the central provinces that are relatively more advanced are neighbors of coastal provinces. The "pushing effects" and "pulling effects" that they benefit from both directions encourage their rapid development, which may favor their catching-up vis-à-vis the coastal neighbors and their "standing-out" vis-à-vis the other inland provinces. The western provinces benefit from the growth of the central neighbors. However, the spillover effects of the western provinces on the growth of their central neighbors are not significant. ${ }^{33}$

\footnotetext{
${ }^{33}$ The limited sample size impedes the estimation of the spillover effects of GAWRL and GAWPL separately among the Western provinces.
} 
Table 3 - Growth spillover effects among coastal provinces

\begin{tabular}{|c|c|c|c|c|c|c|c|c|c|}
\hline Dependent variable: $\ln \left(y_{i, t}\right)-\ln \left(y_{i, t-1}\right)$ & (1) & (2) & $\left(2^{\prime}\right)$ & (3) & (3') & (4) & $(4 ')$ & (5) & $\left(5^{\prime}\right)$ \\
\hline \multirow[t]{2}{*}{$\ln \left(y_{i, t-1)}\right.$} & $-1.397 * * *$ & $-1.277 * * *$ & $-1.302^{* * *}$ & $-1.767 * * *$ & $-1.770 * * *$ & $-1.047^{* *}$ & $-1.165^{* *}$ & $-1.516 * * *$ & $-1.505 * * *$ \\
\hline & $(-3.77)$ & $(-3.31)$ & $(-3.36)$ & $(-3.25)$ & $(-3.28)$ & $(-2.10)$ & $(-2.29)$ & $(-2.63)$ & $(-2.61)$ \\
\hline \multirow[t]{2}{*}{$\ln \left(D P_{i, t}\right)$} & $-5.275^{* * *}$ & $-4.954^{* * *}$ & $-5.009 * * *$ & $-6.775 * * *$ & $-6.807 * * *$ & $-4.196 * *$ & $-4.459 * *$ & $-6.658 * * *$ & $-6.659 * * *$ \\
\hline & $(-3.49)$ & $(-3.17)$ & $(-3.18)$ & $(-2.93)$ & $(-3.00)$ & $(-2.14)$ & $(-2.22)$ & $(-2.95)$ & $(-2.95)$ \\
\hline \multirow{2}{*}{$\ln (S i, t)$} & 0.024 & $0.036 * *$ & $0.036 * *$ & $0.062 * * *$ & $0.062 * * *$ & $0.041^{* *}$ & $0.038 *$ & $0.036^{*}$ & $0.036^{*}$ \\
\hline & (1.59) & (2.14) & (2.10) & (3.08) & (3.10) & (1.99) & (1.84) & (1.88) & $(1.87)$ \\
\hline \multirow[t]{2}{*}{$\ln \left(n_{i, t}\right)$} & $-0.839 * * *$ & $-0.915^{* * *}$ & $-0.917 * * *$ & $-1.097 * *$ & $-1.102^{* *}$ & $-0.929 * * *$ & $-0.952 * * *$ & -0.665 & -0.718 \\
\hline & $(-2.97)$ & $(-3.18)$ & $(-3.17)$ & $(-2.23)$ & $(-2.27)$ & $(-2.92)$ & $(-2.93)$ & $(-1.43)$ & $(-1.55)$ \\
\hline \multirow[t]{2}{*}[\operatorname{ln}(DP_{i,t})]{$\times\left[\ln \left(D P_{i, t}\right)\right]$} & $0.273^{* * *}$ & $0.258 * * *$ & $0.261^{* * *}$ & $0.347 * * *$ & $0.349 * * *$ & $0.220 * *$ & $0.232 * *$ & $0.332 * * *$ & $0.331^{* * *}$ \\
\hline & (3.40) & (3.12) & (3.13) & $(2.80)$ & (2.86) & $(2.12)$ & $(2.20)$ & $(2.80)$ & $(2.80)$ \\
\hline \multirow[t]{2}{*}[\operatorname{ln}(DP_{i,t})]{$\times\left[\ln \left(y_{i, t-1}\right)\right]$} & $0.144^{* * *}$ & $0.132 * * *$ & $0.134 * * *$ & $0.173^{* * *}$ & $0.173 * * *$ & $0.108^{* *}$ & $0.120 * *$ & $0.140 * *$ & $0.139 * *$ \\
\hline & (3.61) & (3.17) & (3.21) & (2.87) & $(2.90)$ & $(2.01)$ & (2.19) & (2.17) & (2.15) \\
\hline \multirow[t]{2}{*}{ GAWCOMLi,t } & & $0.166^{*}$ & & & & & & & \\
\hline & & $(1.76)$ & & & & & & & \\
\hline \multirow[t]{2}{*}{ GAWCOMRLi,t } & & & & 0.010 & & & & & \\
\hline & & & & (0.09) & & & & & \\
\hline \multirow[t]{2}{*}{ GAWCOMPLi,t } & & & & & & $0.263^{* *}$ & & & \\
\hline & & & & & & $(2.57)$ & & & \\
\hline \multirow[t]{2}{*}{ GAWCOFLi,t } & & & & & & & & 0.101 & \\
\hline & & & & & & & & (1.09) & \\
\hline Constant & $\begin{array}{c}25.827 * * * \\
\quad(3.60)\end{array}$ & $\begin{array}{c}24.088 * * * \\
\quad(3.24)\end{array}$ & $\begin{array}{c}24.401^{* * *} \\
\quad(3.26)\end{array}$ & $\begin{array}{c}33.547 * * * \\
(3.11)\end{array}$ & $\begin{array}{c}33.701^{* * * *} \\
\quad(3.18)\end{array}$ & $\begin{array}{c}20.310^{* *} \\
(2.17)\end{array}$ & $\begin{array}{c}21.753^{* *} \\
(2.28)\end{array}$ & $\begin{array}{c}33.713 * * * \\
(3.13)\end{array}$ & $\begin{array}{c}33.751^{* * *} \\
\quad(3.13)\end{array}$ \\
\hline Observation number & 208 & 199 & 199 & 120 & 120 & 159 & 159 & 139 & 139 \\
\hline Adjusted R square & 0.7391 & 0.7507 & 0.7459 & 0.8213 & 0.8213 & 0.7493 & 0.7359 & 0.7966 & 0.7943 \\
\hline
\end{tabular}

Note: $t$-students are in parentheses. * significant at 10 percent ; ** significant at 5 percent ; *** significant at 1 percent. 
Table 4 -Growth spillover effects among inland provinces

\begin{tabular}{|c|c|c|c|c|c|}
\hline Dependent variable: $\ln \left(y_{i, t}\right)-\ln \left(y_{i, t-1}\right)$ & (1) & (2) & $\left(2^{\prime}\right)$ & (3) & $\left(3^{\prime}\right)$ \\
\hline $\ln \left(y_{i, t-1}\right)$ & $\begin{array}{c}-0.137 * * * \\
(-5.20)\end{array}$ & $\begin{array}{c}-0.136 * * * \\
(-5.06)\end{array}$ & $\begin{array}{c}-0.131^{* * *} \\
(-4.86)\end{array}$ & $\begin{array}{c}-0.187 * * * \\
(-3.84)\end{array}$ & $\begin{array}{c}-0.188 * * * \\
(-3.85)\end{array}$ \\
\hline $\ln (D P, t)$ & $\begin{array}{c}-0.254 * * * \\
(-3.11)\end{array}$ & $\begin{array}{c}-0.292 * * * \\
(-3.44)\end{array}$ & $\begin{array}{c}-0.307 * * * \\
(-3.60)\end{array}$ & $\begin{array}{c}-0.337 * * * \\
(-2.83)\end{array}$ & $\begin{array}{c}-0.374 * * * \\
(-3.18)\end{array}$ \\
\hline $\ln (S i, t)$ & $\begin{array}{l}-0.013 \\
(-1.02)\end{array}$ & $\begin{array}{l}-0.010 \\
(-0.71)\end{array}$ & $\begin{array}{l}-0.013 \\
(-0.95)\end{array}$ & $\begin{array}{c}-0.052 * \\
(-1.87)\end{array}$ & $\begin{array}{c}-0.066^{* *} \\
(-2.48)\end{array}$ \\
\hline $\ln \left(n_{i, t}\right)$ & $\begin{array}{c}-0.798 * \\
(-1.95)\end{array}$ & $\begin{array}{c}-0.686 * \\
(-1.70)\end{array}$ & $\begin{array}{c}-0.692 * \\
(-1.70)\end{array}$ & $\begin{array}{l}-0.659 \\
(-0.79)\end{array}$ & $\begin{array}{l}-0.914 \\
(-1.11)\end{array}$ \\
\hline GAWINMLi,t & & $\begin{array}{c}0.208^{* *} \\
(2.24)\end{array}$ & & & \\
\hline GAWINFLi,t & & & & $\begin{array}{c}0.221^{*} \\
(1.67)\end{array}$ & \\
\hline Constant & $\begin{array}{c}2.678^{* * * *} \\
(3.58)\end{array}$ & $\begin{array}{c}3.002^{* * *} \\
(3.85)\end{array}$ & $\begin{array}{c}3.138 * * * \\
(4.01)\end{array}$ & $\begin{array}{c}3.371^{* * * *} \\
(3.25)\end{array}$ & $\begin{array}{c}3.697 * * * \\
(3.61)\end{array}$ \\
\hline Observation number & 360 & 348 & 348 & 154 & 154 \\
\hline Adjusted R square & 0.5325 & 0.5533 & 0.5460 & 0.6285 & 0.6200 \\
\hline
\end{tabular}

The significance of the positive spillover effects holds for the Chinese provinces as a whole, as well as for the different sub-groups. However, some provinces have more significant spillover effects on the others. In this case, the relatively less advanced coastal provinces act as "locomotives" that pull and push the development of their neighbors. Some provinces benefit from the spillover effects disproportionately, for example, the relatively more developed central provinces enjoy the pushing and pulling effects from their neighbors. In this regard, the polarization of the most developed coastal provinces and the catching-up of the relatively rich central provinces could be expected due to the strong spillover effects that they enjoy. 
Table 5 - Growth spillover effects among central and western provinces

\begin{tabular}{|c|c|c|c|c|c|c|c|c|c|c|c|c|c|}
\hline Dependent Variable: & (1) & (2) & (2') & (3) & (3') & (4) & $\left(4^{\prime}\right)$ & (5) & (5') & (6) & (6') & (7) & (7') \\
\hline & Central & Central & Central & Central & Central & Central & Central & Central & Central & Western & Western & Western & Western \\
\hline $\ln \left(y_{i, t-1}\right)$ & $-0.160 * * *$ & $-0.172 * * *$ & $-0.169 * * *$ & $-0.226 * * *$ & $-0.212 * * *$ & $-0.102 *$ & $-0.110^{* *}$ & $-0.138 *$ & $-0.139 *$ & $-0.127 * * *$ & $-0.127 * * *$ & $-0.116^{* *}$ & -0.144 \\
\hline & $(-3.77)$ & $(-3.87)$ & $(-3.72)$ & $(-3.78)$ & $(-3.64)$ & $(-1.90)$ & $(-2.01)$ & $(-1.69)$ & $(-1.71)$ & $(-3.43)$ & $(-3.44)$ & $(-2.06)$ & $(-2.53)$ \\
\hline $\ln (D P, t)$ & $-0.249 * *$ & $-0.341 * * *$ & $-0.365 * * *$ & $-0.261^{* *}$ & $-0.278 * *$ & $-0.326 * *$ & $-0.354 * * *$ & -0.226 & -0.240 & $-0.212^{*}$ & $-0.212^{*}$ & -0.137 & -0.272 \\
\hline & $(-2.30)$ & $(-3.04)$ & $(-3.20)$ & $(-2.07)$ & $(-2.22)$ & $(-2.60)$ & $(-2.80)$ & $(-0.89)$ & $(-0.97)$ & $(-1.66)$ & $(-1.67)$ & $(-0.83)$ & $(-1.68)$ \\
\hline $\ln \left(S_{i, t}\right)$ & -0.026 & -0.015 & -0.016 & -0.033 & -0.037 & -0.0396 & -0.043 & 0.001 & 0.001 & 0.004 & 0.005 & -0.041 & -0.044 \\
\hline & $(-1.17)$ & $(-0.60)$ & $(-0.62)$ & $(-1.02)$ & $(-1.16)$ & $(-1 . .36)$ & $(-1.45)$ & $(0.04)$ & $(0.04)$ & $(0.20)$ & $(0.27)$ & $(-1.29)$ & $(-1.34)$ \\
\hline $\ln \left(n_{i, t}\right)$ & $-2.124 * * *$ & $-1.641^{* *}$ & $-1.834 * * *$ & $-1.981^{* *}$ & $-2.023^{* *}$ & $-2.050 * *$ & $-2.216 * * *$ & -1.426 & -1.429 & -0.054 & -0.078 & -0.658 & -0.453 \\
\hline & $(-3.03)$ & $(-2.37)$ & $(-2.61)$ & $(-2.37)$ & $(-2.42)$ & $(-2.50)$ & $(-2.66)$ & $(-1.33)$ & $(-1.34)$ & $(-0.10)$ & $(-0.15)$ & $(-0.83)$ & $(-0.55)$ \\
\hline$G A W C E M L_{i, t}{ }^{\mathrm{a}}$ & & $\begin{array}{c}0.309 * * * \\
(2.71)\end{array}$ & & & & & & & & & & & \\
\hline GAWCEMRLi,t & & & & $\begin{array}{l}0.1472 \\
(1.04)\end{array}$ & & & & & & & & & \\
\hline GAWCEMPLi,t & & & & & & $\begin{array}{c}0.224 * * \\
(2.13)\end{array}$ & & & & & & & \\
\hline GAWCEFL $L_{i, t}$ & & & & & & & & $\begin{array}{l}0.057 \\
(0.33)\end{array}$ & & & & & \\
\hline GAWWEMLi,t $^{\mathrm{b}}$ & & & & & & & & & & $\begin{array}{l}-0.097 \\
(-0.69)\end{array}$ & & & \\
\hline GAWWEFLi,t & & & & & & & & & & & & $\begin{array}{c}0.539 * * * \\
(2.76)\end{array}$ & \\
\hline Constant & $\begin{array}{c}2.630 * * * \\
(2.70)\end{array}$ & $\begin{array}{c}3.438 * * * \\
(3.40)\end{array}$ & $\begin{array}{c}3.664 * * * \\
(3.56)\end{array}$ & $\begin{array}{c}2.866 * * * \\
(2.60)\end{array}$ & $\begin{array}{c}2.976 * * * \\
(2.71)\end{array}$ & $\begin{array}{c}3.110 * * * \\
(2.71)\end{array}$ & $\begin{array}{c}3.394 * * * \\
(2.92)\end{array}$ & $\begin{array}{l}2.360 \\
(1.09)\end{array}$ & $\begin{array}{l}2.492 \\
(1.18)\end{array}$ & $\begin{array}{l}2.346^{*} \\
(1.96)\end{array}$ & $\begin{array}{l}2.346^{*} \\
(1.96)\end{array}$ & $\begin{array}{l}1.505 \\
(0.99)\end{array}$ & $\begin{array}{c}2.845 * \\
(1.90)\end{array}$ \\
\hline $\begin{array}{l}\text { Observation number } \\
\text { Adjusted R square }\end{array}$ & $\begin{array}{c}180 \\
0.6157\end{array}$ & $\begin{array}{c}174 \\
0.6492\end{array}$ & $\begin{array}{c}174 \\
0.6310\end{array}$ & $\begin{array}{c}125 \\
0.6901\end{array}$ & $\begin{array}{c}125 \\
0.6865\end{array}$ & $\begin{array}{c}132 \\
0.6430\end{array}$ & $\begin{array}{c}132 \\
0.6267\end{array}$ & $\begin{array}{c}95 \\
0.6883\end{array}$ & $\begin{array}{c}95 \\
0.6878\end{array}$ & $\begin{array}{c}174 \\
0.5547\end{array}$ & $\begin{array}{c}174 \\
0.5532\end{array}$ & $\begin{array}{c}117 \\
0.5929\end{array}$ & $\begin{array}{c}117 \\
0.5573\end{array}$ \\
\hline
\end{tabular}

Note: $t$-students are in parentheses. * significant at 10 percent ; ** significant at 5 percent ; *** significant at 1 percent. (a) $C E$ stands for Central provinces; (b) WE stands for Western provinces. 


\section{Section 4: Provincial growth spillover effects simulation}

Spillover effects from and onto a province differ. We will examine the effect of growth of different provinces on regional development by simulating a hypothetical performance enhancement.

By construction, the change in the growth rate of the province $q\left(g a_{q, t}\right)$ leads to the change of the indicator of "neighbor performance" of its neighbor provinces $i$ - the indicator $G A W L i, t$ will have a new value $\operatorname{GAWL}(q)_{i, t}$. Given the fact that the economic environment plays a significant role in regional growth, the modification of the indicator $\operatorname{GAWL}(q)_{i, t}$ will result in a modification of performance of neighbor provinces $i$. The greater the relative economic size of province $q$, the larger the induced effects on the performance of province $i$, others being equal. By simulating the spillover effects of each province $q$ on different neighbor provinces and regrouping the latter into geographic regions, we can examine the effectiveness of the regional growth pattern, and identify the provinces that serve as "locomotives" (which have the strongest positive spillover effects on the neighbors) for the development of China as a whole, and of the coastal provinces, the inland provinces, and the western provinces in particular.

To capture the heterogeneity of the spillover effects from and on coastal/inland provinces, we sub-classify the indicators GAWL according to the geographic position of the each province and its neighbours to simulate the impacts of a $10 \%$ hypothetical increase in the growth rate of each province $q .{ }^{34}$ Here, the type of indicator "neighbor performance", noted as $G A W X_{i, t}$, is conditioned on the geographic position of the province that generates the spillover effects and that of the province that receives the spillover effects. $X$ is specified by two codes: "CO" or " $I N$ ", and " $M$ " or " $F$ " -- the coding " $C O$ " or " $I N$ " depends on the geographic position of the recipient province; while the coding " $M$ " or " $F$ " depends on the whether province that generates the

\footnotetext{
${ }^{34}$ Specifically, we use the equation 2 of table 3 to estimate the spillover effects from coastal neighbours on the coastal provinces; the equation 5 of table 3 from inland neighbours on the coastal provinces; the equation 2 of table 4 from inland neighbours on the inland provinces; and the equation 3 of table 4 from coastal neighbours on inland provinces.
} 
spillover effect is in the same geographic region of the recipient. For example, when we simulate the impact of a $10 \%$ hypothetical increase in the growth rate of Hebei (a coastal province) on Henan (an inland province), we use GAWINFi,t ; when we simulate the impact of a $10 \%$ hypothetical increase in the growth rate of Hebei on Beijing (a coastal province), we use GAWCOMi,t . We calculate the weighted average growth rate of the recipient's neighbours of the corresponding specific type. ${ }^{35}$

First, we calculate the estimated value of the dependent variable $\ln \left(y_{i, t}\right)-\ln \left(y_{i, t-1}\right)$ of the model, noted as gaesw $w_{i, t}$, by using the actual value of the indicator "neighbor performance", $G A W X_{i, t}$, that we construct with the observed value of the growth rate of neighbor provinces $q$ and of the other controlling variables, including "initial development", "peripheral degree", "investment rate" and "demographic growth rate", and by applying the values of the coefficients $\left(\alpha, \rho, \theta, \gamma, \zeta, \vartheta, \chi_{t}\right)$ that we have estimated.

Second, we multiply the growth rate $\left(g a_{q, t}\right)$ of province $q(q=1,2,3, \ldots 28)$ by $110 \%$, and obtain a new value of specific indicator "GAWX $X_{i, t}$ ", noted as "GAWX(q)i,t ". Hence, we obtain the new value of $G A W X L, t$, which is induced by the modification of $g a_{q, t}$, noted as $\operatorname{GAWXL}(q)_{i, t}$.

Third, we replace $G A W X L_{i, t}$ with $G A W X L(q)_{i, t}$ into the equation above. By applying the values of the coefficients $\left(\alpha, \rho, \theta, \gamma, \zeta, \vartheta, \chi_{t}\right)$ that we have estimated earlier, we calculate the value of the dependent variable $\ln \left(y_{i, t}\right)-\ln \left(y_{i, t-1}\right)$, noted as $\operatorname{gaesw}(q)_{i, t}$.

Fourth, we define $\operatorname{gadifw}(q)_{i, t}=\operatorname{gaesw}(q)_{i, t}-$ gaeswi,t $_{\mathrm{i}}$, which stands for the increase of the growth rate of province $i$ in time $t$ induced by the $10 \%$ enhancement of the growth rate of province $q$ in time $t-1$.

\footnotetext{
${ }^{35}$ We tried more detail "sub-grouping" of the provinces groups into central and western, and sub-classify provinces according to their relative richness level. It is in fact a trade-off between imposing the "hypothesis of the similarity of spillover effects from and on different provinces" and losing number of observations (because not all provinces have all types of neighbour provinces, when we increase the homogeneity of provinces, spillover generator and recipient, we get small samples). We believe that the coastal/inland sub-grouping is the optimal one which best respects the heterogeneity of the spillover effects among different groups without losing too many observations. Results of other sub-grouping are available upon request.
} 
Fifth, we calculate the weighted average of the spillover effects on the provinces $i$ to examine the effects induced by the change of $g a_{q, t}$ on different geographic groups. We weigh the spillover effects of each province $i$ by its relative economic size in the group, and note the spillover effects of province $q$ on the region in question in time $t$ as $\operatorname{gaeffw}(q) t$.

$$
\operatorname{gaeffw}(q)_{t}=\sum_{i}^{n}\left[\operatorname{gadifw}(q) i,+\frac{G D P_{, t}}{\sum_{i}^{n} G D P, t}\right]
$$

Finally, to evaluate the effects due to the change of $g a_{q, t}$ of different provinces $q$ on the growth of all the Chinese provinces as a whole, of the coastal provinces, of the inland province and of the western provinces, we calculate the following ratios:

1) $i \in$ all Chinese provinces, gaeffw $(q)_{t}$ stands for the effects of growth on the Chinese provinces as a whole due to a hypothetical $10 \%$ increase in the growth rate of the province $q$ in time $t$, noted gaeffw0(q) ;

2) $i \in$ all coastal provinces, gaeffw $(q)$ t stands for the effects of growth on the coastal provinces due to a hypothetical $10 \%$ increase in the growth rate of the province $q$ in time $t$, noted gaeffw $1(q)_{t}$;

3) $i \in$ all coastal provinces, gaeffw $(q)$ stands for the effects of growth on the inland provinces due to a hypothetical 10\% increase in the growth rate of the province $q$ in time $t$, noted gaeffw2(q)t;

4) $i \in$ all coastal provinces, gaeffw $(q)$ stands for the effects of growth on the western provinces due to a hypothetical $10 \%$ increase in the growth rate of the province $q$ in time $t$, noted gaeffw3(q)t.

For the sake of simplicity, we study the average induced effects during the period 1980-1999 by calculating the following variables respectively ${ }^{36}$ :

\footnotetext{
${ }^{36}$ We suppose that the "induced effects" of the hypothetical growth enhancement of the province $q$ on itself are zero, when we calculate the spillover effects of the group that the province $q$ belongs to. The
} 
gaeffw0 $(q) m=\frac{\sum_{1980}^{1999} g a e f f w 0(q) t}{20}$

gaeffw $1(q) m=\frac{\sum_{1980}^{1999} g a e f f w 1(q) t}{20}$

$\operatorname{gaeffw2}(q) m=\frac{\sum_{1980}^{1999} g a e f f w 2(q) t}{20}$

$\operatorname{gaeffw} 3(q) m=\frac{\sum_{1980}^{1999} g a e f w f 3(q) t}{20}$

The higher the value of the series of the indicators gaeffw $(q) m$, the greater the spillover effects of province $q$ on the group of provinces in question.

The column "national" in table 6 shows that a hypothetical 10\% increase in the growth rate of some coastal provinces, including Hebei, Jiangsu, Guangdong, Shandong, Fujian and Zhejiang leads to the greatest performance increase at the national level. These six provinces are among those that experienced the fastest growth since $1978 .{ }^{37} \mathrm{In}$ this regard, their rapid take-off, which leads to the largest aggregate growth spillover effects on the entire economy, can be considered as a regional development pattern that maximize national growth. In particular, the fast growth of Guangdong has been strongly favouring its inland neighbours. ${ }^{38}$

results of the induced effects of each province $q$ on the performance of different groups (all Chinese provinces, coastal provinces, inland provinces and western provinces) in each year are available upon request.

${ }^{37}$ Zhejiang, Fujian, Guangdong, Jiangsu, and Shandong are the five provinces that grew fastest, with an average annual growth rate higher than 10\% for the whole period of 1978-1999 (table 1).

${ }^{38}$ Our simulation results are robust to the modification of the hypothetical growth enhancement. Annex 3 shows that the rankings of the size of the spillover effects that different provinces have on the whole China and on each region do not change much if we do not distinguish the spillover effects from and to coastal and inland provinces but simply use the equation 2 of table 2 to simulate the spillover effects for all countries. We have also tested the robustness of the ranking by simulating the effects if the growth rate of each province increases $10 \%$ of the national level (in this case, the absolute hypothetical growth enhancement of each province is the same, no matter the province in question had a high growth rate or low growth rate). In this case, the ranking does not change much either. Results are available upon request. 
Table 6 - The regional growth induced by a hypothetical $10 \%$ enhancement of the performance of different provinces (coastal vs. inland)

\begin{tabular}{|c|c|c|c|c|c|c|c|c|}
\hline & Nat & nal & $\mathrm{Coa}$ & & & & We & tern \\
\hline & Province & Average & Province & Average & Province & Average & Province & Average \\
\hline 1 & Ningxia & 0.02 & Shanxi & $\ldots$ & Beijing & $\ldots$ & Beijing & $\ldots$ \\
\hline 2 & Xinjiang & 0.03 & Nei Mongol & $\ldots$ & Tianjin & ... & Tianjin & ... \\
\hline 3 & Qinghai & 0.06 & Jilin & $\ldots$ & Shanghai & $\ldots$ & Hebei & ... \\
\hline 4 & Guangxi & 0.15 & Heilongjiang & $\ldots$ & Ningxia & 0.04 & Liaoning & $\ldots$ \\
\hline 5 & Tianjin & 0.19 & Anhui & $\ldots$ & Xinjiang & 0.07 & Jilin & $\ldots$ \\
\hline 6 & Beijing & 0.21 & Jiangxi & $\ldots$ & Qinghai & 0.12 & Heilongjiang & $\ldots$ \\
\hline 7 & Guizhou & 0.21 & Henan & $\ldots$ & Fujian & 0.24 & Shanghai & $\ldots$ \\
\hline 8 & Shanxi & 0.22 & Hubei & $\ldots$ & Guangxi & 0.33 & Jiangsu & ... \\
\hline 9 & Yunnan & 0.25 & Hunan & $\ldots$ & Guizhou & 0.46 & Zhejiang & ... \\
\hline 10 & Heilongjiang & 0.27 & Guangxi & $\ldots$ & Shanxi & 0.48 & Anhui & $\ldots$ \\
\hline 11 & Jiangxi & 0.31 & Sichuan & $\ldots$ & Yunnan & 0.55 & Fujian & $\ldots$ \\
\hline 12 & Gansu & 0.36 & Guizhou & $\ldots$ & Heilongjiang & 0.58 & Jiangxi & ... \\
\hline 13 & Jilin & 0.43 & Yunnan & $\ldots$ & Jiangxi & 0.67 & Shandong & $\ldots$ \\
\hline 14 & Anhui & 0.54 & Shaanxi & $\ldots$ & Jiangsu & 0.75 & Ningxia & 0.06 \\
\hline 15 & Nei Mongol & 0.55 & Gansu & $\ldots$ & Gansu & 0.78 & Shanxi & 0.19 \\
\hline 16 & Shaanxi & 0.55 & Qinghai & $\ldots$ & Jilin & 0.93 & Xinjiang & 0.20 \\
\hline 17 & Hunan & 0.68 & Ningxia & $\ldots$ & Zhejiang & 0.95 & Qinghai & 0.33 \\
\hline 18 & Shanghai & 0.69 & Xinjiang & $\ldots$ & Liaoning & 1.15 & Nei Mongol & 0.48 \\
\hline 19 & Liaoning & 0.72 & Tianjin & 0.34 & Nei Mongol & 1.18 & Guangxi & 0.51 \\
\hline 20 & Henan & 0.78 & Liaoning & 0.36 & Shaanxi & 1.19 & Henan & 0.53 \\
\hline 21 & Sichuan & 1.12 & Beijing & 0.40 & Anhui & 1.20 & Guizhou & 1.00 \\
\hline 22 & Hubei & 1.38 & Guangdong & 0.53 & Hunan & 1.48 & Shaanxi & 1.23 \\
\hline 23 & Zhejiang & 1.60 & Shanghai & 1.26 & Henan & 1.71 & Yunnan & 1.47 \\
\hline 24 & Fujian & 1.72 & Shandong & 1.70 & Shandong & 2.07 & Gansu & 1.90 \\
\hline 25 & Shandong & 1.87 & Zhejiang & 2.15 & Hebei & 2.13 & Hubei & 2.57 \\
\hline 26 & Guangdong & 1.93 & Fujian & 2.95 & Sichuan & 2.42 & Hunan & 2.63 \\
\hline 27 & Jiangsu & 2.42 & Hebei & 3.09 & Hubei & 3.02 & Guangdong & 2.74 \\
\hline 28 & Hebei & 2.64 & Jiangsu & 3.84 & Guangdong & 3.59 & Sichuan & 3.69 \\
\hline
\end{tabular}

Note: Figures are presented in 1/10000. " ... " stands for the figures inferior to 0.0000005 . For example, a 10 percent increase annual growth rate in Hebei province leads to a $2.64 \times 10^{-4}$ increase of the growth rate of the whole China. Coastal provinces are marked in italics.

However, if we look closely into the distribution of these positive spillover effects from the coastal locomotives at regional level, the results of the last three columns suggest that the induced growth mainly concentrates in the coastal region and their effects on the inland region (and western region) are very limited. The resulting widening regional development gap is inconsistent with the objective of balanced growth. To generate the optimal spillover effects on the catching-up of the inland/western provinces, development aid should be targeted towards the inland hubs, Hubei and Sichuan, for their rapid growth might not only has large spillover effects on the inland/western regions, but also on the entire Chinese economy. 


\section{Conclusions}

The rapid take-off of some coastal provinces since the beginning of the economic reforms generated the largest aggregate growth spillover effects on the entire Chinese economy, but at the expense of a widening regional development gap. This paper argues that a policy of encouraging the growth of the non-coastal regional hubs, such as Sichuan and Hubei, would have strong forward and backward linkages with the inland/western regions and thus reduce the regional development gap without sacrificing much aggregate growth.

\section{Reference:}

Amiti M., Javorcik B. (2004), "Trade cost and location of foreign firms in China”, paper presented in ABCDE 2004, Economists' Forum, The World Bank.

Bao S., Chang G.H., Sachs J.D., Woo W.T. (2003), "Geographic factors and China's regional development under market reforms, 1978-1998", China Economic Review, Vol.13, No.1, pp. 89-111.

Barro R.J. (1991), "Economic growth in a cross section of countries", Quarterly Journal of Economics, Vol.106, No.2 (May), pp. 407-443.

Barro R.J., Sala-i-Martin (1995), Economic Growth, New York: McGraw-Hill, Inc.

Baumont C., Ertur C., Le Gallo J. (2001), " Spatial econometric analysis of geographic spillovers and growth for European regions, 1980-1995 ", presentation of the 6th RSAI World Congress 2000 "Regional Science in a small world ", Lugano, Switzerland.

Ben-David D. (1994), "Convergence clubs and diverging economies", CEPR discussion paper 922.

Ben-David D. (1997), "Convergence clubs and subsistence economies", NBER working paper 6267

Bergstrand J.H. (1985), "The gravity equation in international trade: some microeconomic foundations and empirical evidence", The Review of Economics and Statistics, August 1985, pp. 474-481.

Berthelemy J.C., Demurger S. (2000), "Foreign direct investment and economic growth: theory and application to China, Review of Development Economics, Vol.4, No.2., pp.140-155.

Chuang Y., Hsu P. (2004), "FDI, trade, and spillover efficiency: evidence from China's manufacturing sector”, Applied Economics, Vol.36, pp.1103-1115.

Chen J., Fleisher B.M. (1996), "Regional income inequality and economic growth in China", Journal of Comparative Economics, Vol.22, pp. 141-164.

Courcier M., Lafay G. (1972), "Simulation économique multinationale", Statistique \& Etudes Financières, 1972/8, $4^{\text {ème }}$ trimestre.

Cozzi G. (1997), "Exploring growth trajectories", Journal of Economic Growth, Vol.2, No.4, pp.385-398.

Deardorff A. (1995), "Determinants of bilateral trade: does gravity work in a neoclassical world?", NBER working paper No.5377.

Démurger S., Sachs J.D., Woo W.T., Bao S. (2002), "Geography, economic policy and regional development in China", Asia Economic Papers, Vol.1., No. 1. 
Desdoigts A. (1999), "Patterns of economic development and the formation of clubs", Journal of Economic Growth, Vol.4 (September), pp.305-330.

Easterly W., Levine R. (1995), “Africa's growth tragedy: a retrospective, 1960-89”, Policy Research Working Paper No.1503, The World Bank.

Eaton J., Tamura A. (1994), "Bilateralism and regionalism in Japanese and U.S. trade and foreign direct investment patterns”, Journal of the Japanese and International Economies, Vol.8, No.4, pp.478-510.

Eaton J., Kortum S. (1994), "International patenting and technology diffusion”, NBER Working Paper No.4931.

Evenett S., Keller W. (1998), "On Theories Explaining the Success of the Gravity Equation", NBER working paper 6529.

Fujita M., Krugman P., Venables A.J. (1999), The spatial economy: Cities, regions and international trade, the MIT Press.

Jian T., Sachs J.D. , Warner A.M. (1996), "Trends in regional inequality in China", NBER working paper 5412.

Krugman P. (1991), "Geography and Trade", Leuwen University Press and the MIT press, Cambridge, MA.

Krugman P. (1993a), “First nature, second nature and metropolitan location”, Journal of Political Economy, No.99, pp.129-144.

Krugman P. (1993b), "On the number and location of cities", European Economic Review, No.37., pp.293-305.

Krugman P. (1998), "What's new about the new economic geography?", Oxford Review of Economic Policy, Vol.14, No.2, pp.7-17.

Limao N., Venables A.J. (2001), "Infrastructure, geographical disadvantage, transport costs, and trade", World Bank Economic Review, Vol.15, No.3, pp.451-479.

Luo X. (2001), "L'accessibilité au marché des provinces chinoises: le rôle des 'hubs' de transport", Revue Région et Développement, No.14, pp.121-142.

Luo X. (2004), "The Role of Infrastructure Investment Location on China's Western Development", Policy Research Working Paper No.3345, The World Bank.

McCallum J. (1995), "National borders matter: Canada- U.S. regional trade patterns", American Economic Review, Vol. 85, No.3, pp.615-623.

Moreno R., Trehan B. (1997), "Location and the growth of nations", Journal of Economic Growth, Vol.2, No.4, pp.399-418.

National Bureau of Statistics of China (1987), Statistics of China's Fixed Assets and Investment 1950-1985, Beijing, Chinese Statistics Press.

National Bureau of Statistics of China (1999), Comprehensive Statistical Data and Materials on 50 Years of New China, Beijing : China Statistics Press.

Naughton B. (1995), Growing Out of The Plan: Chinese Economic Reform, 1978-1993, New York: Cambridge University Press, 1995.

Naughton B. (1999), "Causes et conséquences des disparités dans la croissance économique des provinces chinoises", Revue d'Economie du Développement, Vol.7, No.1-2, pp.33-70

Poncet S. (2003), "Measuring Chinese Domestic and International Integration”, China Economic Review, vol. 14(1), 1-21.

Qian Y. (2000), "The Process of China's Market Transition (1978-1998): The Evolutionary, Historical, and Comparative Perspectives." Journal of Institutional and Theoretical Economics, 156(1), 151-171.

Qian Y. (2003), "How Reform Worked in China?" in Dani Rodrik, editor, In Search of Prosperity: Analytic Narratives on Economic Growth, Princeton University Press, 297333.

Quah D. (1996), "Twin peaks: growth and convergence in models of distribution dynamics", Economic Journal, Vol.106, pp.1045-1055. 
Quah D. (1997), "Empirics for growth and distribution: Stratification, polarization, and convergence clubs", Journal of Economic Growth, Vol.2, No.1, pp.27-59.

Quah D. (1999), "Ideas determining convergence clubs", site web: http://econ.lse.ac.uk/staff/dquah/p/9907ccb.pdf

Redding S., Venables A.J. (2000), "Economic geography and international inequality", CEPR working paper 2568.

Renard M.F. ed. (2002), China and it regions: Economic growth and reform in Chinese provinces, Edward Elgar.

State Statistical Bureau of the People's Republic of China, China Statistical Yearbook (19861999), China Statistics Press, Beijing.

Yilmaz S., Haynes K.E., Dinc M. (2002), “Geographic and network neighbours: spillover effects of telecommunications infrastructure”, Journal of Regional Science, Vol.42, No.2, pp.339-360.

Zhang Q., Felmingham B. (2002), “The role of FDI, exports and spillover effects in the regional development of China”, Journal of Development Studies, Vol.38, No.4, pp.157-178. 


\section{Annex 1. Map of China}

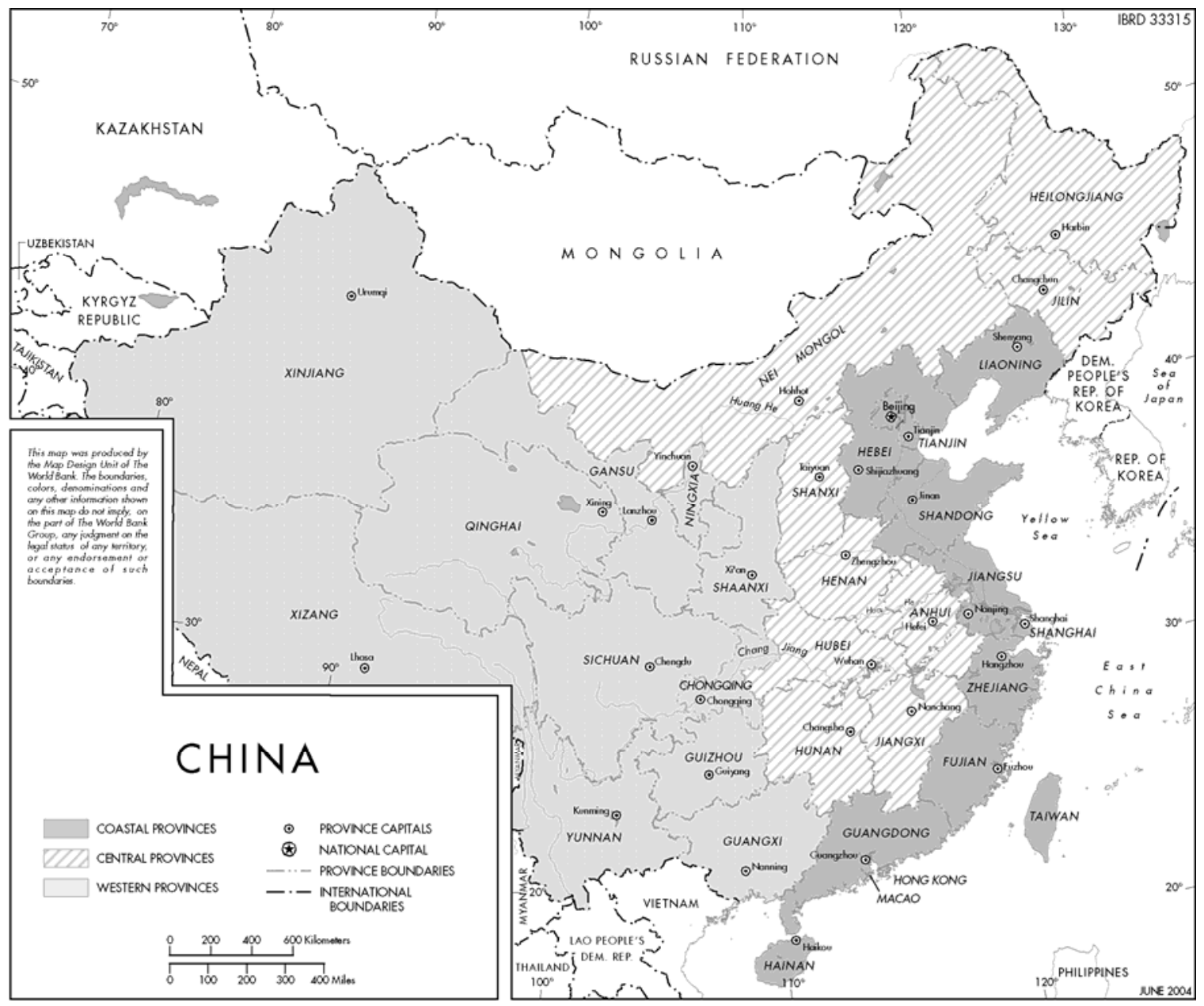




\section{Annex 2 Construction of the indicator "Peripheral Degree"}

The construction of the Peripheral degree of a province (province i) includes five steps:

1. For each province (noted as province v), we calculate its road density and railway density, noted as $D R_{v, t}$ and $D F_{v, t}$ respectively. Then, to better reflect the importance of road transportation and the railway transportation, we weight them with the road transportation volume and the railway transportation volume to get the transportation network index of the province ( $\left.D_{v, t}\right)$ :

$$
D_{v, t}=a_{1 t} D R_{v, t}+a_{2 t} D F_{v, t} .
$$

Where $a_{1 t}$ represents the percentage of the road transportation volume and $a_{2 t}$ represents that of the railway at time t. $\mathrm{a}_{1 \mathrm{t}}+\mathrm{a}_{2 \mathrm{t}}=1$.

2. For each two provinces (province i and province j), we calculate the index of the transportation facility between them, noted $D_{i j, t}$. Suppose that to transport some goods from province i to province $\mathrm{j}$, it should go through n provinces (province i and j included), we take the index $D_{i j, t}$ as the simple average of the value of $D_{v, t}$ of these n provinces:

$$
D_{i j, t}=\frac{\sum D_{v, t}}{n}
$$

3. We define the real distance between province i and province j ( $D_{i s t} t_{i j, t}$ ) as the weighted sum of their road distance ( $D_{i s t R_{i j, t}}$ ) and railway distance ( $D i s t F_{i j, t}$ ).

$$
\operatorname{Dist}_{i j, t}=a_{1 t} \text { Dist }_{i j, t}+a_{2 t} \operatorname{DistF}_{i j, t}
$$

4. We define the adjusted real distance between province i and province $\mathrm{j}\left(\operatorname{Dist} A_{i j, t}\right.$ ) as the result of their real distance divided by the index of their transportation facility.

$$
\operatorname{DistA}_{i j, t}=\text { Dist }_{i j, t} / D_{i j, t}
$$

For a given real distance, the adjusted real distance implies that, the better the transportation facility is, the less the adjusted distance is. The transportation facility "shortens" the economic distance between the two provinces by reducing the transportation cost. The adjusted real distance is a better proxy of the transportation cost. The shorter the adjusted real distance is, the less the trade obstacles between two partners and so the greater the volume of trade between them, other things being equal. The greater the trade volume is between two provinces, the better the market accessibility is to the other in the view of the province in question, and the influence of partner province's demand on the local market is greater.

5. We define the peripheral degree of province $i$ as the weighted sum of the adjusted distance between this province and the domestic economic centers (here, the coastal provinces).

$$
D P_{i, t}=\sum_{j}\left(\operatorname{DistA}_{i j, t} \times \frac{G D P_{j, t}}{\sum_{j} G D P_{j, t}}\right)
$$

We weigh the adjusted distance between the province in question $(i)$ and a coastal province $(j)$ by the economic mass of the latter relative to that of coastal provinces in total to approximate the relative importance of the effective remoteness. The reason lies in that the farther away the province in question is from a great size coastal province, the more serious the disadvantage is that it suffers. The higher is the peripheral degree, the lower the economic-geographic attractiveness of the location. 
Annex 3- The regional growth induced by a hypothetical $10 \%$ enhancement of the performance of different provinces without distinguishing sub-group spillover effects

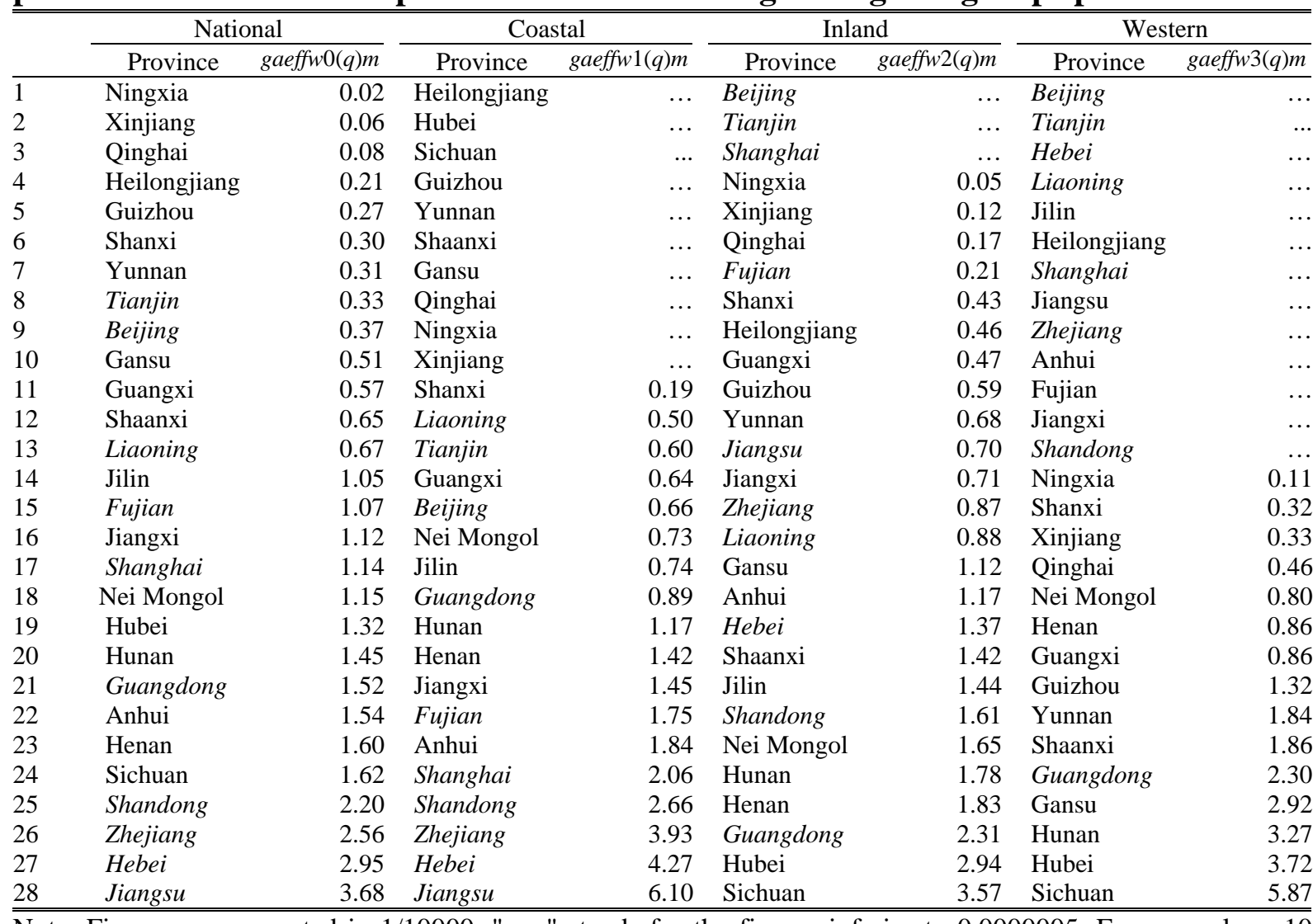

Note: Figures are presented in $1 / 10000 . "$ " ... " stands for the figures inferior to 0.0000005 . For example, a 10 percent increase annual growth rate in Jiangsu province leads to a $3.68 \times 10^{-4}$ increase of the growth rate of the whole China. Coastal provinces are marked in italics. 